\title{
Sources of pharmaceutical pollution in the New York City Watershed
}

\author{
Patrick M. Palmer ${ }^{a}$, Lloyd R. Wilson ${ }^{a, c, *}$, Patrick O'Keefe ${ }^{b, c}$, Robert Sheridan $^{b, 1}$, \\ Thomas King ${ }^{b, 1}$, Chia-Yang Chen ${ }^{b, 2}$
}

a Bureau of Water Supply Protection, Center for Environmental Health, New York State Department of Health, Troy, NY, $12180-2216$ USA

biggs Laboratory, Wadsworth Center, New York State Department of Health, Empire State Plaza, P.O. Box 509, Albany, NY 12201-0509 USA

${ }^{\mathrm{c}}$ School of Public Health, University at Albany, One University Place, Rensselaer, NY, 12144-3456 USA

\section{A R T I C L E I N F O}

Article history:

Received 24 September 2007

Received in revised form

2 January 2008

Accepted 4 January 2008

Available online 15 February 2008

Keywords:

Pharmaceuticals

Surface water

Wastewater effluent

\begin{abstract}
A B S T R A C T
An investigation was carried out in the New York City Watershed for the presence of selected pharmaceuticals. In four seasonal sampling events between August 2003 and May 2004, surface water was collected from eight reservoir keypoints and effluent was collected from four wastewater treatment plants. We evaluated the following twelve compounds: amoxicillin, atenolol, caffeine, carbamazepine, cephalexin, estrone, $17 \alpha$-ethinylestradiol, $17 \beta$-estradiol, ibuprofen, sulfamethoxazole, trimethoprim, and valproic acid. In the treated effluents, carbamazepine was detected most frequently (100\%; concentration range: $22-$ $551 \mathrm{ng} / \mathrm{L})$, followed by atenolol (94\%; ND — 14,200 ng/L), trimethoprim (83\%; ND - 37,000 ng/ L), ibuprofen (61\%; ND - 14,600 ng/L), and caffeine (49\%; ND - 37,200 ng/L), while estrone was detected once $(56 \mathrm{ng} / \mathrm{L})$. In the reservoir keypoint samples, only ibuprofen (2.5\%; ND $932 \mathrm{ng} / \mathrm{L})$ and caffeine $(2.9 \%$; ND $-177 \mathrm{ng} / \mathrm{L})$ were detected. The other analytes were not detected in any sample. It is expected that investigation of other wastewater treatment plants in the New York City Watershed would show that their effluents are also a potential source of pharmaceuticals, but that these pharmaceuticals are unlikely to be detected in the Watershed's surface waters.
\end{abstract}

(c) 2008 Elsevier B.V. All rights reserved.

\section{Introduction}

Pharmaceuticals have been detected in wastewater treatment plant effluents, surface water, ground water, and drinking water. Most drug classes have been documented, including analgesics, antibiotics, antiepileptics, antihypertensives, anti- septics, beta-blocker heart drugs, contraceptives, hormones, lipid-lowering drugs, psychotherapeutics, and X-ray contrast media (Halling-Sørenson et al., 1998). According to the National Association of Chain Drug Stores, Americans filled over 3.2 billion prescriptions in 2003, an increase of over 1 billion since 1995 (NACDS, 2005). U.S. spending for prescription drugs is

\footnotetext{
* Corresponding author. BWSP, NYSDOH, 547 River Street, Room 400, Troy, NY 12180-2216 USA. Tel.: +1 5184027711 ; fax: +1 5184027759. E-mail address: lrw03@health.state.ny.us (L.R. Wilson).

Abbreviations: NYSDOH, New York State Department of Health; NYC, New York City; WWTP, wastewater treatment plant; HPLC, high performance liquid chromatography; MS, mass spectrometer; ESI, electrospray ionization

${ }^{1}$ Present address: New York State Department of Agriculture and Markets, Building 7, Third Floor, State Office Campus, Albany, NY, 12235 USA.

2 Present address: Institute of Environmental Health, College of Public Health, National Taiwan University, 19 Hsu-Chou Road, Room 737, Taipei City 10055, Taiwan.
} 
projected to increase by 10.1\% annually through 2011 (Heffler et al., 2005), a figure which does not include the much larger overthe-counter drug market. It is expected that as the population of the United States continues to age, pharmaceutical use will continue to grow. Clearly, with the aging of the U.S. population and rising pharmaceutical sales, increases in the potential amount of pharmaceuticals entering the waste stream are probable for the foreseeable future.

The potential for pharmaceuticals to enter the environment is not unique to New York; it has been studied in other waters of North America (Seiler et al., 1999; Kolpin et al., 2002; Stackelberg et al., 2004), South America (Stumpf et al., 1999), and Europe (Ternes, 1998; Buser et al., 1999; McArdell et al., 2003). However, the New York City Watershed is unique: it is the largest engineered surface water storage and supply source in the world (NYCDEP, 2006). It serves about 4.5 million $\mathrm{m}^{3}$ of water daily to approximately 8 million residents of NYC, and 1 million residents in four other southern New York counties (NYCDEP, 2006). This represents almost half of New York State's population. In addition, there are over 100 wastewater treatment plants that discharge treated effluent into the watershed (NYCDEP, 2006), which could be a potential source of contamination to these important source waters. Therefore, we investigated the presence of the selected pharmaceutical compounds in wastewater treatment plant effluents, surface water at reservoir keypoints, and water prior to chlorination and distribution in the NYC water supply.

\section{Study background}

\subsection{Description of NYC Watershed}

The NYC Watershed consists of three water supply systems: Croton, Delaware, and Catskill (Fig. 1). The watersheds of the three systems cover an area of almost $5200 \mathrm{~km}^{2}$. The reservoirs have a combined storage capacity of 2 billion $\mathrm{m}^{3}$. The Croton system has 3 controlled lakes and 12 reservoirs, with the largest being the New Croton Reservoir, with a capacity of 72 million $\mathrm{m}^{3}$. The Croton system normally supplies $10 \%$ of the NYC's drinking water. The Catskill system includes two reservoirs (Schoharie and Ashokan) and supplies up to $40 \%$ of the City's daily needs. The Delaware system consists of four reservoirs: Cannonsville, Pepacton, Neversink, and Rondout. These provide $50 \%$ of the NYC's daily water needs. Water from both the Catskill and Delaware systems usually passes through the Kensico Reservoir, which has a

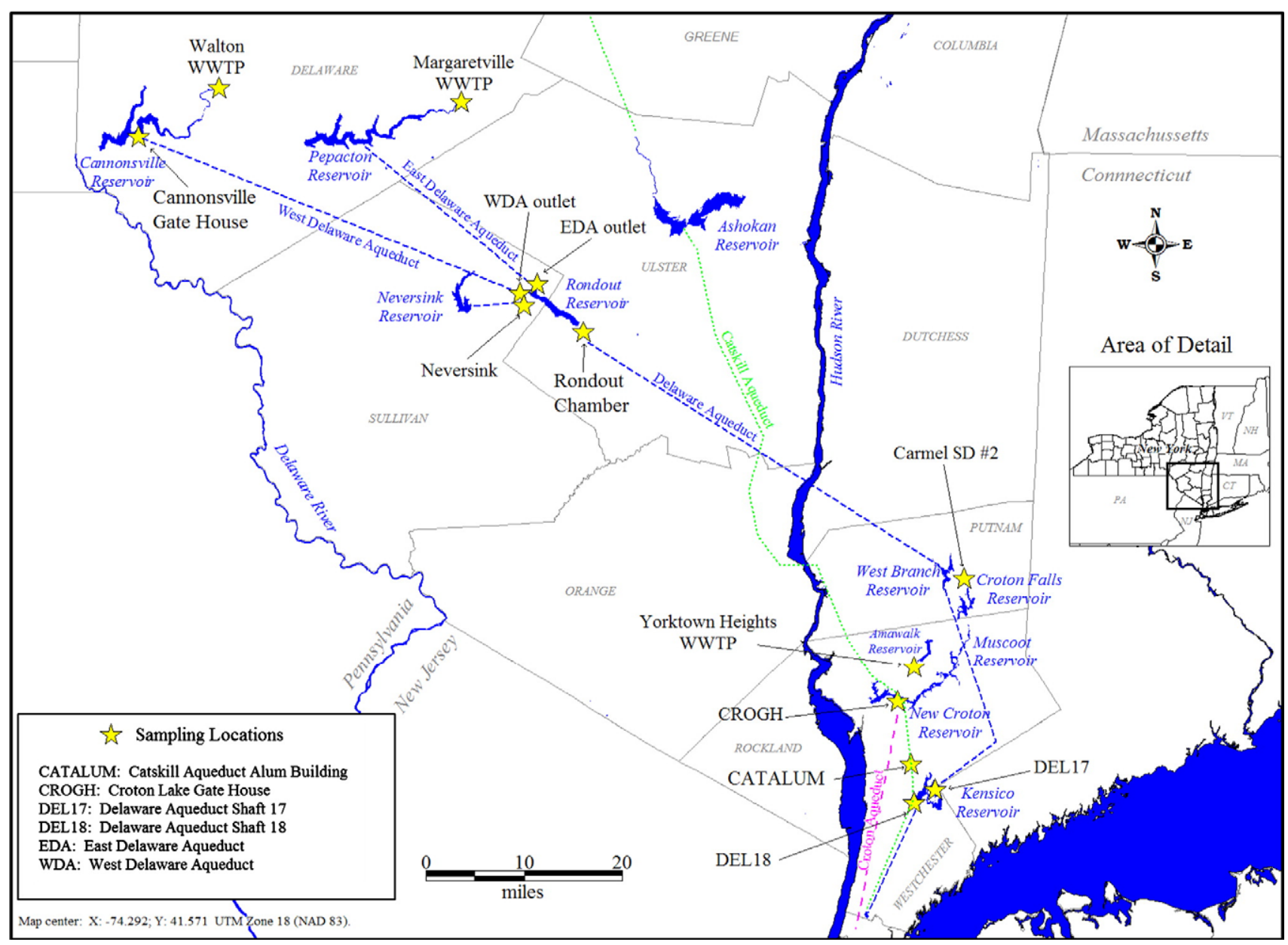

Fig. 1-Map of WWTP and reservoir sampling locations. August 2003-May 2004. 
capacity of 1.16 billion $\mathrm{m}^{3}$ (http://www.ci.nyc.ny.us/html/dep/ watershed/html/reservoirs.html).

\subsection{Sampling locations}

There were twelve primary sampling locations for the study (Fig. 1). On each side of the Hudson River (East side of Hudson, $\mathrm{EOH}$; West side of Hudson, WOH), four surface water locations and two WWTPs were sampled. We collected samples of water exiting the Cannonsville, Neversink, Pepacton, Rondout, New Croton, and Kensico Reservoirs, and water entering the Kensico Reservoir via the Delaware and Catskill Aqueducts. Sampling at the DEL 18 location was prior to chlorination and entrance into the City's distribution system. No samples were collected after chlorination or from NYC's water distribution system.

The four WWTPs in the study serve varied populations and utilize varied treatment techniques, as shown in Table 1. The Carmel and Yorktown Heights plants are located in the Croton Watershed, and the Margaretville and Walton plants are located in the Delaware Watershed. These plants are small by most standards, but typical of many of the WWTPs discharging into the watershed, with daily flows between 1500 and $5700 \mathrm{~m}^{3} /$ day and service area populations ranging from 800 to 10,000. Carmel uses activated sludge with post-aeration to treat waste from a suburban mix of residences and businesses, including a pharmaceutical lab. Yorktown Heights, the oldest of the four plants, uses a trickling filter and coagulation, and has no significant nonresidential sources. Margaretville is the newest and smallest of the four plants. It uses rotating biological contactors, microfiltration, and UV, and its service area includes waste from a hospital. Walton uses aeration and continuous backwash-upflow dual-sand filtration, and its service area includes a nursing home and a health care facility. None of the plants uses a combined sewer collection system.

\subsection{Sample collection}

During each of the four calendar seasons (beginning in August 2003 and ending in May 2004), 4-L grab samples were collected for seven consecutive days at each of 12 locations. Samples were collected in silanized 4-L amber glass bottles that were rinsed three times with the sample water prior to collection. On the sampling day, the surface water samples were collected before the WWTP effluent samples to minimize the potential for cross-contamination. An additional sample was collected on the first, third, fifth, and seventh days of each sampling event for quality control purposes; this duplicate was collected at least once for each location over the course of the study.

\subsection{Selection of analytes}

Analyte selection was based on a qualitative evaluation of a number of factors that would suggest the presence of these compounds in the WWTP effluent and/or the environment. Factors considered were the following: number of prescriptions written per year, amount of the drug in a daily dose, information on drug absorption and metabolism in humans, environmental degradation, and previous research (Kolpin et al., 2002). Table 2 lists 2004 prescription data for the analytes. Caffeine was also included because it is an established marker for human waste. The laboratory method was developed specifically for the eleven selected compounds.

\section{Analytical methods}

\subsection{Chemicals and reagents}

Amoxicillin, 17 $\alpha$-ethinylestradiol, 17 $\beta$-estradiol, atenolol, caffeine, carbamazepine, cefadroxil, cephalexin, estrone, ibuprofen,

Table 1 - Characteristics of WWTPs and the populations served ${ }^{\text {a }}$

\begin{tabular}{|c|c|c|c|c|}
\hline & Carmel SD \#2 & Yorktown Heights & Margaretville & Walton \\
\hline Year built & 1965 & 1961 & 1998 & 1978 \\
\hline Year updated & 1999 & 1973 & - & 2002 \\
\hline Collection system & Separate & Separate & Separate & Separate \\
\hline Biotreatments used & $\begin{array}{l}\text { Conventional activated sludge; } \\
\text { step aeration activated sludge; SC }\end{array}$ & $\mathrm{SC}^{\mathrm{b}}$; trickling filter & $\begin{array}{l}\text { Rotating biological } \\
\text { contactor; SC }\end{array}$ & Extended aeration \\
\hline Filters & $\mathrm{FSR}^{\mathrm{c}}$ & $\begin{array}{l}\text { Intermittent sand filters; } \\
\text { FSR }\end{array}$ & $\begin{array}{l}\text { Microfiltration-membrane; } \\
\text { FSR }\end{array}$ & Microfiltration-CBUDS $^{\mathrm{d}}$ \\
\hline $\begin{array}{l}\text { Additional } \\
\text { treatment }\end{array}$ & $\mathrm{PA}^{\mathrm{e}}$ & $\begin{array}{l}\text { Chemical coagulation and } \\
\text { settling; PA; } \mathrm{PR}^{\mathrm{f}}\end{array}$ & $\begin{array}{l}\text { Breakpoint chlorination; } \\
\text { chemical coagulation and } \\
\text { settling; NR } \text {; PR }\end{array}$ & $\begin{array}{l}\text { Nutrient feed-ammonia; } \\
\text { PR }\end{array}$ \\
\hline Design flow (MGD) & 0.35 & 1.5 & 0.4 & 1.17 \\
\hline $\begin{array}{l}\text { Population served } \\
\text { (approx.) }\end{array}$ & 3000 & 10,000 & 800 & 3500 \\
\hline Population type & Suburban & Suburban & Rural & Rural \\
\hline Significant sources & Pharmaceutical lab & None known & Hospital & $\begin{array}{l}\text { Nursing home, health } \\
\text { care facilities }\end{array}$ \\
\hline \multicolumn{5}{|c|}{$\begin{array}{l}\text { a From NYSDEC, } 2004 . \\
\text { b SC: secondary clarifier. } \\
\text { c FSR: rapid sand high rate filters. } \\
\text { d } \text { CBUDS: continuous backwash-upflow, dual-sand filtration. } \\
\text { e PA: post-aeration. } \\
\text { f } \text { PR: phosphorus removal. } \\
\text { g NR: nitrogen removal. }\end{array}$} \\
\hline
\end{tabular}




\section{Table 2 - Total prescription (Rx) count ${ }^{\mathrm{a}}$ of study analytes in the United States, 2004}

\begin{tabular}{|c|c|c|c|c|c|c|}
\hline Rank & Product & Type & $\begin{array}{l}\text { Total Rx count } \\
\text { (in millions) }\end{array}$ & $\begin{array}{l}\text { Total Rx count \% } \\
\text { change prior year }\end{array}$ & $\begin{array}{l}\text { Avg dosage } \\
\text { (mg/day) }\end{array}$ & $\begin{array}{c}\text { Metric tons purchased } \\
\text { (estimated) }\end{array}$ \\
\hline 1 & Atenolol & Generic/beta-blocker & 44.2 & 2.9 & 50 & 66 \\
\hline 2 & Amoxicillin & Generic/antibiotic & 41.4 & 10.5 & 1000 & 414 \\
\hline 10 & Cephalexin & Generic/antibiotic & 23.7 & -0.2 & 1000 & 237 \\
\hline 14 & Ibuprofen & Generic/pain relief & 25.2 & 0.7 & 1600 & $565^{f}$ \\
\hline $26^{\mathrm{d}}$ & Sulfamethoxazole & Generic/antibiotic & 13.6 & 3.3 & 800 & 109 \\
\hline $26^{\mathrm{d}}$ & Trimethoprim & Generic/antibiotic & 13.6 & 3.3 & 160 & 22 \\
\hline 86,134 & Sodium valproate ${ }^{\mathrm{e}}$ & Brand/antiepileptic & 8.2 & -4.0 & 1000 & 246 \\
\hline 125 & Carbamazepine & Generic/anticonvulsant & 2.7 & -4.1 & 400 & 32.4 \\
\hline Various & $17 \alpha$-Ethinylestradiol & Generic/hormone & $41.6^{\mathrm{g}}$ & Various & Various & 0.04 \\
\hline Various & $17 \beta$-Estradiol & Generic/hormone & $10.0^{\mathrm{h}}$ & Various & Various & 0.01 \\
\hline Unknown & Estrone & Generic/hormone & Unknown & Unknown & Unknown & Unknown \\
\hline
\end{tabular}

${ }^{a}$ Modified from NDCHealth Corp. (2005). Information based on NDCHealth proprietary methodologies. Reflects prescription data for retail, mail order, and institutional pharmacy channels. Available at: www.drugtopics.com and http://www.ndchealth.com/press_center/ uspharmaindustrydata/2004top10productsbytotalprescription.htm.

b,c Average doses and tons purchased were calculated using information from www.rxlist.com and www.pdrhealth.com assuming one antibiotic prescription covers a 10-day dosing period; one ibuprofen prescription covers 14 days; $17 \alpha$-ethinylestradiol and $17 \beta$-estradiol cover 28 days, other drugs assume one prescription covers a 30-day dosing period.

${ }^{\mathrm{d} S u l f a m e t h o x a z o l e ~ a n d ~ t r i m e t h o p r i m ~ a r e ~ g e n e r a l l y ~ p r e s c r i b e d ~ i n ~ c o m b i n a t i o n . ~ T h e ~ c o u n t ~ g i v e n ~ i s ~ f o r ~ t h e ~ c o m b i n e d ~ p r e s c r i p t i o n s . ~}$

ePrescriptions listed are combined for sodium valproate (Depakote, 5.0 million, $-14.5 \%$; Depakote ER, 3.2 million, 15.3\%).

f Ibuprofen metric tons purchased does not include over-the-counter sales.

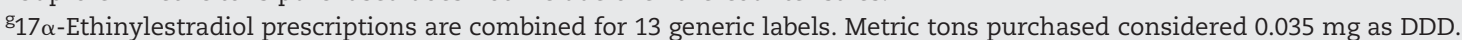

${ }_{1} 17 \beta$-Estradiol prescriptions are combined for Vivelle-DOT, Climara, and generic estradiol oral. Metric tons purchased considered $0.05 \mathrm{mg}$ as DDD Caffeine was not included, as it is not a prescribed drug.

sulfamethoxazole, trimethoprim, valproic acid, deuterium dioxide, 4-methylmorpholine, and $\mathrm{D}_{2} \mathrm{SO}_{4}$ were purchased from Sigma Chemical (St. Louis, MO, USA). Caffeine (trimethyl $-{ }^{13} \mathrm{C}_{3}$ ), $17 \beta$-estradiol $\left(2,4,16,16^{\prime}-d_{4}\right)$, isovanillic acid (ring- $\left.{ }^{13} \mathrm{C}_{6}\right)$, phenacetin (ethoxy-1-1 ${ }^{13} \mathrm{C}$ ), sulfamethazine (phenyl $-{ }^{13} \mathrm{C}_{6}$ ), valproic acid $\left(1,2,3,3^{\prime}-{ }^{13} \mathrm{C}_{4}\right)$, and vanillic acid (carboxyl- ${ }^{13} \mathrm{C}$ ) were purchased from Cambridge Isotope Laboratories (Andover, MA, USA). Practolol was purchased from Tocris (Ellisville, MO, USA) and $d_{10}$-carbamazepine from $\mathrm{C} / \mathrm{D} / \mathrm{N}$ Isotopes Inc. (Quebec, Canada). Dr. Chuck Litterst from the Division of AIDS (National Institute of Allergy and Infectious Diseases, Bethesda, MD, USA) donated tetroxoprim. The $d_{4}$-ibuprofen was synthesized using $\mathrm{D}_{2} \mathrm{SO}_{4}$ and ibuprofen. The following chemicals and materials were also used: acetone, acetonitrile, ethyl acetate, and methanol, all HPLC grade (Burdick \& Jackson from VWR Scientific, West Chester, PA, USA); 88\% formic acid, and 100-200 $\mu \mathrm{m}$ silica gel (Mallinckrodt Baker Inc., Paris, KY, USA); 37-53 $\mu \mathrm{m}$ silica gel and QM-A glass microfiber filter paper (Whatman, Maidstone, UK); ammonium formate (Anachemia Chemicals, Rouses Point, NY, USA); dimethyldichlorosilane (Supelco, Bellefonte, PA, USA); Empore ${ }^{\mathrm{TM}}$ SDB-XC 47-mm poly(styrenedivinylbenzene) extraction discs, and Empore ${ }^{\mathrm{TM}}$ Filter Aid 400 (3M, St. Paul, MN, USA); Carboprep 200 extraction cartridges, $200 \mathrm{~m}^{2} / \mathrm{g}$ carbon surface area, and $500 \mathrm{mg}$ bed weight (Restek, Bellefonte, PA, USA).

\subsection{Solid-phase extraction}

3.2.1. Acid/neutral analytes (17 $\alpha$-ethinylestradiol, 17 $\beta$-estradiol, estrone, ibuprofen, and valproic acid)

Water samples (2 L) were adjusted to $\mathrm{pH} 2.5$ using $3.4 \mathrm{~mL} \mathrm{88 \%}$ formic acid and spiked with $20 \mu \mathrm{L}$ of a mixture of internal standards ( $d_{4}$-ibuprofen, $17 \beta$-estradiol $\left[2,4,16,16^{\prime}-d_{4}\right]$, and val- proic acid $\left.\left[1,2,3,3^{\prime}-{ }^{13} \mathrm{C}_{4}\right]\right)$ in methanol, with each standard at $10 \mathrm{ng} / \mu \mathrm{L}$. Individual samples were extracted using a Teflon housing containing in sequence, from top-to-bottom: glass microfiber filter paper, a 1-cm layer of Filter Aid 400, glass microfiber filter paper, an SDB-XC extraction disk, and a fine mesh nylon screen followed by a wide mesh nylon screen. The assembly was then placed on a Speedisk Expanded Extraction Station (Mallinckrodt Baker, Paris, KY, US). The disk was conditioned with $15 \mathrm{~mL}$ of acetone, $15 \mathrm{~mL}$ of methanol and $20 \mathrm{~mL}$ of $\mathrm{pH} 2.5$ distilled deionized (DDI) water. The sample was passed through the disk under vacuum at a flow rate of $<100 \mathrm{~mL} / \mathrm{min}$.

After the disk had been dried for $\sim 3$ min on high vacuum, the Filter Aid 400 and filter paper were removed, and the disk was then dried for an additional $5 \mathrm{~min}$. Next, the disk was transferred to a Baker SPE 24G Column Processor (Mallinckrodt Baker Inc., Paris, KY, USA) and 3 aliquots of $4 \mathrm{~mL}$ of $\mathrm{pH} 8.5$ methanol (4-methylmorpholine/methanol, 1:1000, v/v) and 3 aliquots of $4 \mathrm{~mL}$ of acetone were used to elute the target compounds from the disk into a scintillation vial. A Turbovap II (Zymark, Hopkinton, MA, USA), was used for concentrating samples to $150 \mu \mathrm{L}$. The water bath temperature was $40^{\circ} \mathrm{C}$, and the nitrogen flow rate was 26 psi. After the addition of $50 \mu \mathrm{L}$ of DDI water the sample was concentrated to a final volume of $100 \mu \mathrm{L}$.

A silica gel microcolumn was used for sample cleanup. The silica gel was made with equal parts of 37-53 $\mu \mathrm{m}$ and 100$200 \mu \mathrm{m}$ mesh silica gel deactivated with $3 \%$ DDI water. About $0.4 \mathrm{~g}$ of this silica gel mixture was sandwiched between Pyrex glass wool in an Eppendorf autopipet tip (Eppendorf, Hamburg, Germany) and the column was conditioned with 3 aliquots of $2 \mathrm{~mL}$ of ethyl acetate/toluene (50:50, v/v). The sample extract was then loaded onto the silica gel, and the 
target compounds were eluted with 5 aliquots of $2 \mathrm{~mL}$ of toluene/ethyl acetate $(85: 15, \mathrm{v} / \mathrm{v})$, by $\mathrm{N}_{2}$ pressure. In the next step, the cleaned up extract was concentrated to $300 \mu \mathrm{L}$ and then $100 \mu \mathrm{L}$ DDI water was added. When a final volume of $90 \mu \mathrm{L}$ was reached, the sample was transferred into a microvial insert for analysis and spiked with $10 \mu \mathrm{L}$ of a $10-\mathrm{ng} / \mu \mathrm{L}$ methanol solution of the recovery standard, isovanillic acid (ring- ${ }^{13} \mathrm{C}_{6}$ ).

3.2.2. Basic/amphoteric analytes (amoxicillin, atenolol, caffeine, carbamazepine, cephalexin, sulfamethoxazole, and trimethoprim) For these analytes, all glassware had to be silanized. The manufacturer silanized the inserts and microvials, and all other glassware was silanized in the laboratory. The silanizing was performed by rinsing with a solution of $10 \%$ dimethlydichlorosilane in toluene, followed by two rinses with toluene and then two rinses with methanol. Since it was impractical to segregate glassware, the silanized glassware was also used in the analysis of the acid/neutral compounds.

Carboprep cartridges were placed on a Baker SPE 24G Column Processor and conditioned with $5 \mathrm{~mL}$ of pH 2.5 DDI water, followed by $5 \mathrm{~mL}$ of DDI water. Samples $(1 \mathrm{~L})$ were spiked with $25 \mu \mathrm{L}$ of an internal standard mixture in methanol, which contained cefadroxil, ampicillin, caffeine (trimethyl- ${ }^{13-}$ $\mathrm{C}_{3}$ ), practolol, sulfamethazine (phenyl $-{ }^{13} \mathrm{C}_{6}$ ), and tetroxoprim at concentrations varying from $1-400 \mathrm{ng} / \mu \mathrm{L}$. The samples were then loaded onto the cartridges through Teflon tubing, and the vacuum was adjusted to produce a steady flow rate of about $15 \mathrm{~mL} / \mathrm{min}$. After loading, the cartridges were dried under high vacuum for $10 \mathrm{~min}$. The target compounds were eluted from the cartridges, with 2 aliquots of $5 \mathrm{~mL}$ of $\mathrm{pH} 2.9$ methanol ( $90 \mu \mathrm{L}$ formic acid/100 mL methanol), 2 aliquots of $5 \mathrm{~mL}$ of methylene chloride/methanol (80:20, v/v), and 6 aliquots of $5 \mathrm{~mL}$ of acetone.

Using the Turbovap II, samples were concentrated to $200 \mu \mathrm{L}$ and then $500 \mu \mathrm{L}$ of DDI water was added. When a final concentration of $475 \mu \mathrm{L}$ was reached, samples were spiked with $25 \mu \mathrm{L}$ of a $10-\mathrm{ng} / \mu \mathrm{L}$ methanol solution of the recovery standard, phenacetin (ethoxy-1-13 $\mathrm{C}$ ), and transferred into a microvial for analysis.

\subsection{Chromatographic conditions}

Chromatography was performed using an Agilent 1100 series HPLC instrument (Agilent Technologies, Palo Alto, CA, USA). The injection volumes were $10 \mu \mathrm{L}$ for the acidic analytes and $15 \mu \mathrm{L}$ for the basic analytes. The acidic analytes were separated on a LUNA C18 LC column $(150 \times 2.0 \mathrm{~mm}$ I.D., particle size $3 \mu \mathrm{m}$; Phenomex, Torrance, CA, USA) at a $0.2-\mathrm{mL} / \mathrm{min}$ flow rate with a mobile phase of acetonitrile and a basic buffer of $10 \mathrm{mM} \mathrm{N}$-methylmorpholine ( $\mathrm{pH}$ 9.4). The gradient was from $15 \%$ organic phase to $95 \%$ organic phase in $19 \mathrm{~min}$. A post-run time of 15 min was used in order to insure system equilibration. The basic analytes were separated on an Allure Pentafluoropropyl LC column $(150 \times 3.2 \mathrm{~mm}$ I.D., particle size $5 \mu \mathrm{m}$; Restek, Bellefonte, PA, USA) at a $0.5-\mathrm{mL} / \mathrm{min}$ flow rate with a mobile phase of acetonitrile and an acidic buffer of $8.7 \mathrm{mM}$ ammonium formate and $10 \mathrm{mM}$ formic acid ( $\mathrm{pH}$ 3.5). The gradient was from $15 \%$ organic phase to $95 \%$ organic phase in $14 \mathrm{~min}$. A post-run time of $15 \mathrm{~min}$ was used. The basic/ amphoteric fraction was also used for the analysis of carbamazepine, but chromatography was carried out with the acid method. It was found that carbamazepine was extracted with the basic/amphoteric analytes. However the acid/neutral protocol was required for LC/MS analysis.

\subsection{Mass spectrometry}

A Finnegan LCQ Classic quadrupole ion trap MS (Thermo Finnigan, San Jose, CA, USA), was used as a detector. The ionization was performed by ESI, producing negative molecular ions from the acidic analytes and positive molecular ions from the basic analytes. A single ion monitoring method was used for all of the analytes except for amoxicillin and cephalexin, for which an MS/MS method was used. The Xcalibur software package (Thermo Finnigan, San Jose, CA, USA), was used to control both the HPLC and MS. The ESI source parameter settings were: spray voltage: $4.5 \mathrm{kV}$, nitrogen sheath gas flow rate: 67 arbitrary units (au), capillary voltage $-33 \mathrm{~V}$ and capillary temperature: $200{ }^{\circ} \mathrm{C}$.

\subsection{Data processing}

Calibration curves were constructed to determine the response factor of each analyte relative to the response factor of its internal standard. Six calibration solutions were used with analyte concentrations ranging from the limit of detection (LOD) value to $10 \times$ LOD and a fixed internal standard concentration that varied from 4-6x LOD, depending on the analyte. Each solution was analyzed in triplicate and the average values were plotted as a regression line with analyte areas/internal standard areas on the $y$-axis and analyte concentrations/internal standard concentrations on the $x$ axis. The relative response factor (RRF) was determined from the slope of the line.

The concentrations of individual analytes were determined by the following equation:

$C_{\mathrm{A}}=\frac{\text { Analyte area }}{\text { Int. Std. area }} \times \frac{C_{\text {int }}}{\mathrm{RRF}}$

where $C_{A}=$ analyte concentration $(\mathrm{ng} / \mathrm{L})$ and $C_{\text {int }}=$ internal standard concentration (ng/L).

\subsection{Quality Assurance/Quality Control (QA/QC)}

The sample set for QA/QC consisted of field blanks, field sample duplicates, laboratory blanks (DDI and river water collected from the East Branch of the Delaware River, at a location upstream of the Margaretville WWTP), and laboratory spikes (also DDI and river). There were 56 field blanks (one per sampling day), consisting of 4-L volumes of DDI water taken to the point of sampling and transferred to another 4-L sampling container, then transported back to the laboratory with the field samples. Forty-two laboratory blanks were analyzed with the field samples, some of which were prepared from DDI water and others from river water. Only one sample from this total group of 98 blank samples showed evidence of contamination with a study analyte (trimethoprim at the method detection limit (MDL) of $4 \mathrm{ng} / \mathrm{L}$ ). Prior to starting the project the MDL values for the selected pharmaceuticals were determined 
using a statistical approach established by the USEPA (US Code of Federal Regulations, 2007). The procedure involved spiking seven replicate blank water samples with each pharmaceutical at a concentration resulting in an instrumental signal-tonoise $(\mathrm{S} / \mathrm{N})$ between 2.5 and 5 . A S/N value of 4 was selected for this study. The MDL was then calculated with $99 \%$ confidence that the result was greater than zero by multiplying the standard deviation by 3.14, the Student's $t$ value for 6 degrees of freedom at $p<0.01$. The values (ng/L) found were as follows: valproic acid, 199; ibuprofen, 20; estrone, 30; 17 $\beta$-estradiol, 40; $17 \alpha$-ethinylestradiol, 39; amoxicillin, 367; caffeine, 80; cephalexin, 502; atenolol, 9; sulfamethoxazole, 111; and trimethoprim, 4. Carbamazepine was not included in the MDL study, but its MDL was estimated to be $20 \mathrm{ng} / \mathrm{L}$ based on a signal-tonoise ratio of 3:1.

In many of the spiked samples, we failed to detect either amoxicillin or cephalexin. In those samples where the penicillins were detected, there was an extremely wide range in the recovery data. Four other basic analytes (atenolol, caffeine, sulfamethoxazole, and trimethoprim) were detected in the majority of the spiked samples. However, in one sample there was no signal for atenolol and there were no signals for sulfamethoxazole in four samples. With the exception of three samples the recovery values for caffeine were close to $100 \%$ (average \pm S.D., $118 \pm 35$ ). The recovery values for atenolol, sulfamethoxazole, and trimethoprim were less accurate and precise $(200 \pm 98,103 \pm 102$ and $164 \pm 42$ respectively).

Three internal standards were used in the analysis of the acid/neutral analytes, the ${ }^{13} \mathrm{C}$-labeled analog of valproic acid and the deuterated analogs of ibuprofen and $\beta$-estradiol. In contrast to the basic/amphoteric compounds, where we had to rely on surrogates as internal standards for several compounds, we had labeled analogs for all the acid/neutral analytes, although one labeled analog had to serve as an internal standard for the three estrogens. In general, the recoveries were considerably closer to $100 \%$ than the recoveries found for the basic/amphoteric compounds $(132 \pm 81$ for valproic acid; $139 \pm 104$ for ibuprofen; $70 \pm 37$ for estrone; $90 \pm 43$ for $17 \beta$-estradiol; and $71 \pm 49$ for $17 \alpha$-ethinylestradiol).

Although carbamazepine was not designated as an analyte in the original sampling and analysis protocol, it was later included as an analyte since it was detected frequently in the pilot sampling. During the summer and fall sampling events, only the WWTP effluents were analyzed for carbamazepine. We were unable to prepare spiked QA/QC samples for these two sampling events, as there was no internal standard available. Therefore, carbamazepine results from those field samples can only be considered as estimates. A deuteriumlabeled carbamazepine standard was acquired prior to the winter and spring sampling events; results from spiked QA/QC samples showed recoveries between $82 \%$ and $159 \%$.

The recovery standards phenacetin (ethoxy- $-1{ }^{13} \mathrm{C}$ ) and isovanillic acid (ring $-{ }^{13} \mathrm{C}_{6}$ ) were added, respectively, to the basic/amphoteric and acid/neutral extracts just prior to analysis on the LC/MS system. It was intended that these recovery standards should be used to obtain the absolute recoveries of the internal standards added to the water samples prior to extraction. The absolute recoveries obtained in this manner proved to be erratic and unreliable, probably as a consequence of the differences between the structures of the recovery standards and the internal standards. As an alternative approach to obtaining data on the efficiency of the sample preparation procedure, QA/QC samples were prepared with the analytes added to the water samples prior to extraction and the internal standards were then added to the extracts prior to injection into the LC/MS system. With the exception of the penicillins, the absolute recoveries for the basic/amphoteric compounds were generally in the range of $30 \%$ to $100 \%$, although there were some recovery values outside this range.

Precision data for the field samples were obtained by collecting duplicate field samples during each sampling event. In total, 32 duplicates were collected (4 EOH duplicates and 4 WOH duplicates for each of the four sampling events). No signals for any of the analytes were found in 14 of the 16 duplicates collected at the reservoir keypoints. In the two other surface water duplicates, which were collected from WOH sampling points during the spring sampling, ibuprofen was detected with signal areas exceeding $3 \times \mathrm{S} / \mathrm{N}$, but at a concentration below the MDL. All the duplicates collected from the WWTPs (16 paired samples) had paired positive signals above the MDL for at least one of the five analytes detected in the study (atenolol, caffeine, carbamazepine, ibuprofen, and trimethoprim). In one of these sample pairs caffeine was detected in only one replicate while atenolol, carbamazepine, and trimethoprim were found in both replicates. In the case of ibuprofen, there were extremely large differences in two duplicate sets collected in the summer from the Yorktown WWTP effluent (100 and $22.6 \mathrm{ng} / \mathrm{L}$ from one collection and 154 and $17.7 \mathrm{ng} / \mathrm{L}$ from another collection). At this stage of the project, we did not have a complete understanding of the absolute recovery problems for the acid/ neutral compounds. Consequently, the spike levels for the $\mathrm{acid} /$ neutral internal standards were too low, and we had to use external standards to determine the ibuprofen concentrations in the four samples. For the remaining samples containing ibuprofen (10 sample pairs), and for all the positive samples for the other analytes $(15,9,15$, and 14 sample pairs for atenolol, caffeine, carbamazepine, and trimethoprim, respectively), the data from the first duplicate were plotted against data from the second duplicate. The slopes of the regression lines were very close to the theoretical value of 1.00 (0.88-1.06) and the correlation coefficients were in the range of 0.90 to 0.98 . When the results were expressed as relative percent differences (RPDs), the average RPDs were 33, 29, 35, 33 , and $18 \%$ for ibuprofen, caffeine, atenolol, trimethoprim, and carbamazepine, respectively.

\section{4. $\quad$ Results}

Three hundred sixty-eight samples were collected over the four seasonal sampling events. At least two duplicates were collected at every location during the course of the study. The following are the sample sizes for the summer, fall, winter, and spring sampling periods: Carmel, 7, 8, 7, 7; Margaretville and Walton, 8 each season; Yorktown: 11, 8, 8, 7. Six of the twelve analytes were not detected (amoxicillin, $367 \mathrm{ng} / \mathrm{L}$; cephalexin, 502 ng/L; 17 $\beta$-estradiol, 40 ng/L; 17 $\alpha$-ethinylestradiol, 39 ng/L: sulfamethoxazole, $111 \mathrm{ng} / \mathrm{L}$; and valproic acid, $199 \mathrm{ng} / \mathrm{L})$. 
Estrone, with a detection limit of $30 \mathrm{ng} / \mathrm{L}$, was only detected once. However, every sample collected from the WWTP contained some of the targeted analytes. The same pharmaceuticals were not found in surface water samples, with a few exceptions in samples from EOH locations, where ibuprofen and caffeine were detected infrequently at three sampling points. Because there were few detections of the targeted samples from surface water locations, most of the data analysis in this report is for samples collected from the WWTPs.

Statistical analyses were performed using SAS 9.1 (SAS Institute Inc., Cary, North Carolina). Kruskal-Wallis (a nonparametric one-way analysis of rank scores) was used to determine if differences existed between groups. If a significant difference was found (indicated by $p$-value less than 0.05), the data was log transformed and analyzed using Tukey's studentized range test (though in some cases, Tukey-Kramer was used if sample sizes differed). Non-detects were assigned the value of one-half the MDL for use in these calculations.

\subsection{Wastewater treatment plant results}

A summary of the data for the five pharmaceuticals (atenolol, caffeine, carbamazepine, ibuprofen, and trimethoprim) that were found in samples of the WWTP effluent is provided in Fig. 2. All effluent samples contained at least two of these five analytes. Most notably, caffeine was found at a concentration an order of magnitude higher in the Yorktown WWTP effluent compared to samples from the other three WWTP. Carbamazepine concentrations were very similar between Carmel, Margaretville, and Walton, and these three sites all had significantly higher concentrations than at Yorktown. The other analytes showed substantial variation and differences in mean concentrations detected in the effluent from each of the plants.

Atenolol was detected in all samples from Yorktown and Margaretville, and 28 of 29 samples from Carmel. Concentrations were generally highest at Yorktown (median: $1415 \mathrm{ng} / \mathrm{L}$ ), while the maximum concentration was detected at Carmel $(14,200 \mathrm{ng} / \mathrm{L})$. Walton had significantly lower concentrations than the other sites. The mean concentration of caffeine was higher than any other analyte, though this was mainly driven by Yorktown, where it was detected in every sample, and at concentrations significantly higher than the other sites.

As with some of the other analytes, Yorktown had significantly higher concentrations of ibuprofen than the other three locations, and it was present in every sample (though below the detection limit in one sample). Trimethoprim was detected at every WWTP and with relatively high frequencies (between $70 \%$ and $100 \%$ ), though concentrations at Walton were significantly lower than the other sites. At Carmel, we found a very high concentration in one sample of

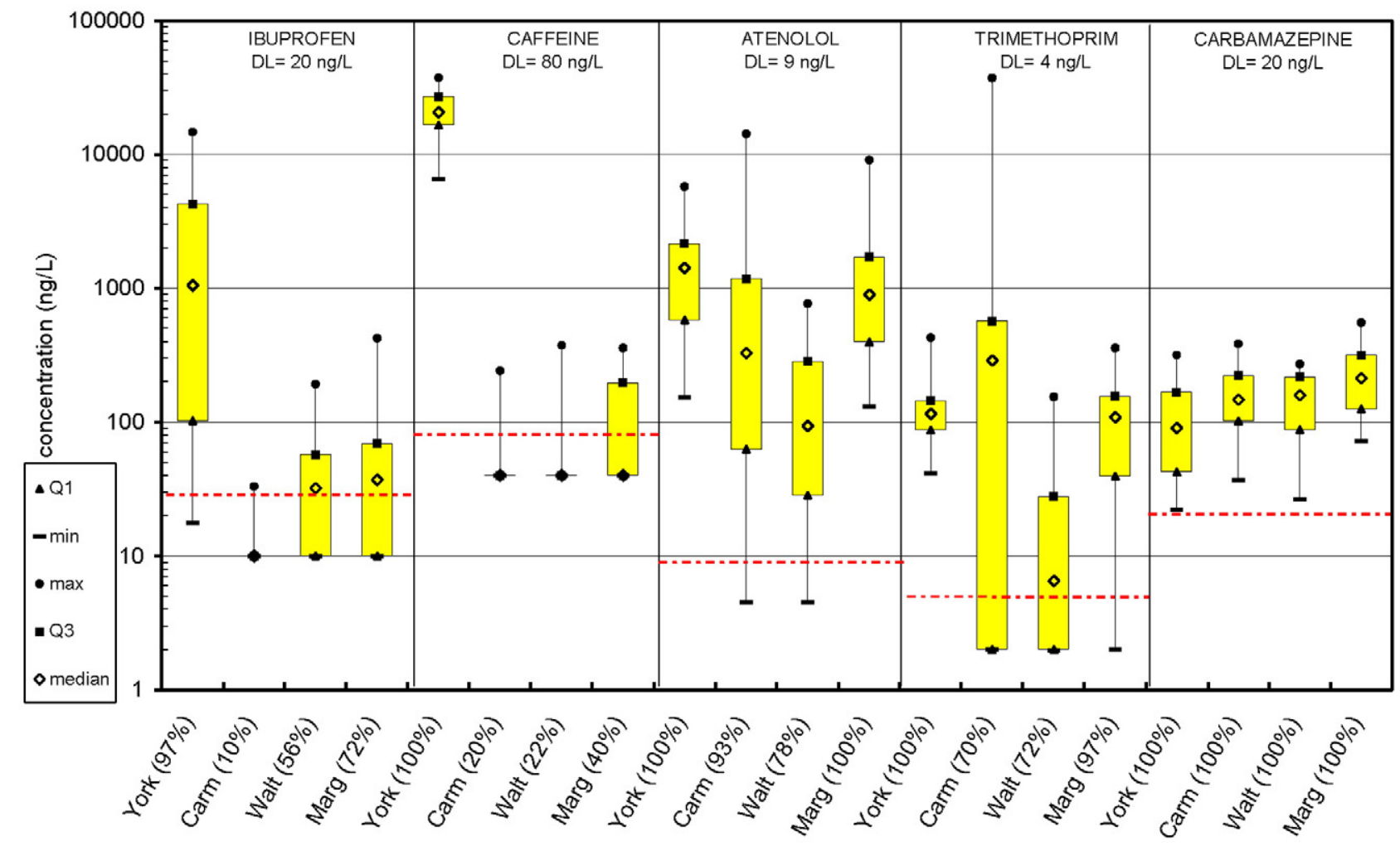

Fig. 2-Concentrations (ng/L) of target analytes in wastewater treatment plant effluents. Note: Dashed line indicates the analyte detection limit. The analytes shown are ibuprofen, caffeine, atenolol, trimethoprim, and carbamazepine. WWTPs are Yorktown $(n=34)$, Carmel $(n=29)$, Walton $(n=32)$, and Margaretville $(n=32)$, with detection frequencies shown on the figure in parentheses. Non-detects were assigned a value of $1 / 2$ the detection limit for that analyte. Q1: 1st quartile; min: minimum; max: maximum; Q3: 3rd quartile. 
$37,000 \mathrm{ng} / \mathrm{L}$, though the second highest concentration there was $8090 \mathrm{ng} / \mathrm{L}$.

\subsection{Results by day}

Although the data are limited (each day of the week average is in most cases comprised of just four samples), concentrations across the seven-day week were generally consistent. Atenolol, caffeine, carbamazepine, and ibuprofen concentrations were consistent at the four treatment plants for the week, as was ibuprofen at all locations except Yorktown (which showed a Saturday decline). Trimethoprim concentrations were more varied, with concentrations at Carmel peaking on Saturdays, but over two orders of magnitude lower on Wednesdays (see Fig. 3).

\subsection{Results by season}

Atenolol concentrations peaked in winter at all four of the WWTPs and with the exception of samples from the summer at Walton, it was found in every sample. At Carmel and Walton, atenolol was higher in the winter than the other seasons $(p<0.05)$. At Yorktown and Margaretville, atenolol was detected in every sample, although at each site, spring concentrations were significantly lower than the other seasons.

In the summer, Yorktown had the highest median caffeine concentration $(29,600 \mathrm{ng} / \mathrm{L})$, which was more than twice that of the winter median, but there were no significant seasonal differences. Seasonal medians at the other three WWTPs ranged from below the detection limit $(<80 \mathrm{ng} / \mathrm{L})$ up to the summer median of $250 \mathrm{ng} / \mathrm{L}$ seen at Margaretville (where it was detected in all eight summer samples). Caffeine was not detected at Carmel, Margaretville, or Walton during the spring sampling period, nor was it detected at Carmel during the summer (see Fig. 4a). The summer sampling at Walton had just one caffeine detection, though it was found in 6 of 8 samples from the fall season.

Generally, the seasonal medians for carbamazepine were similar, especially compared to the wide variations seen with the other analytes (see Fig. 4b). All plants had their highest medians in the winter and lower medians in the summer and fall. (Note that an internal standard was not available for the summer and fall sample analysis.) Winter concentrations at Margaretville were higher than the other seasons, while at Carmel, they were lowest in the fall ( $p<0.05$ for both).

Much like caffeine, seasonal ibuprofen concentrations were generally higher at Yorktown than at the other three WWTPs. It was present in all samples from Yorktown, though it was slightly below the detection limit in one sample. The spring median concentration (5340 ng/L) was over two orders of magnitude higher than the summer median (41 ng/L). At Margaretville, ibuprofen was detected in all samples from the summer and spring, though the detected concentrations showed a much wider range in the summer (37-422 ng/L) than in the spring (35-76 ng/L). At Carmel, ibuprofen was not found above the detection limit (40 ng/L) until the spring sampling, though it was present in one summer sample.

Trimethoprim concentrations at Yorktown were significantly lower in the spring, while at Margaretville, concentrations in the fall were found to be significantly lower than summer and winter, but not spring. Winter and spring

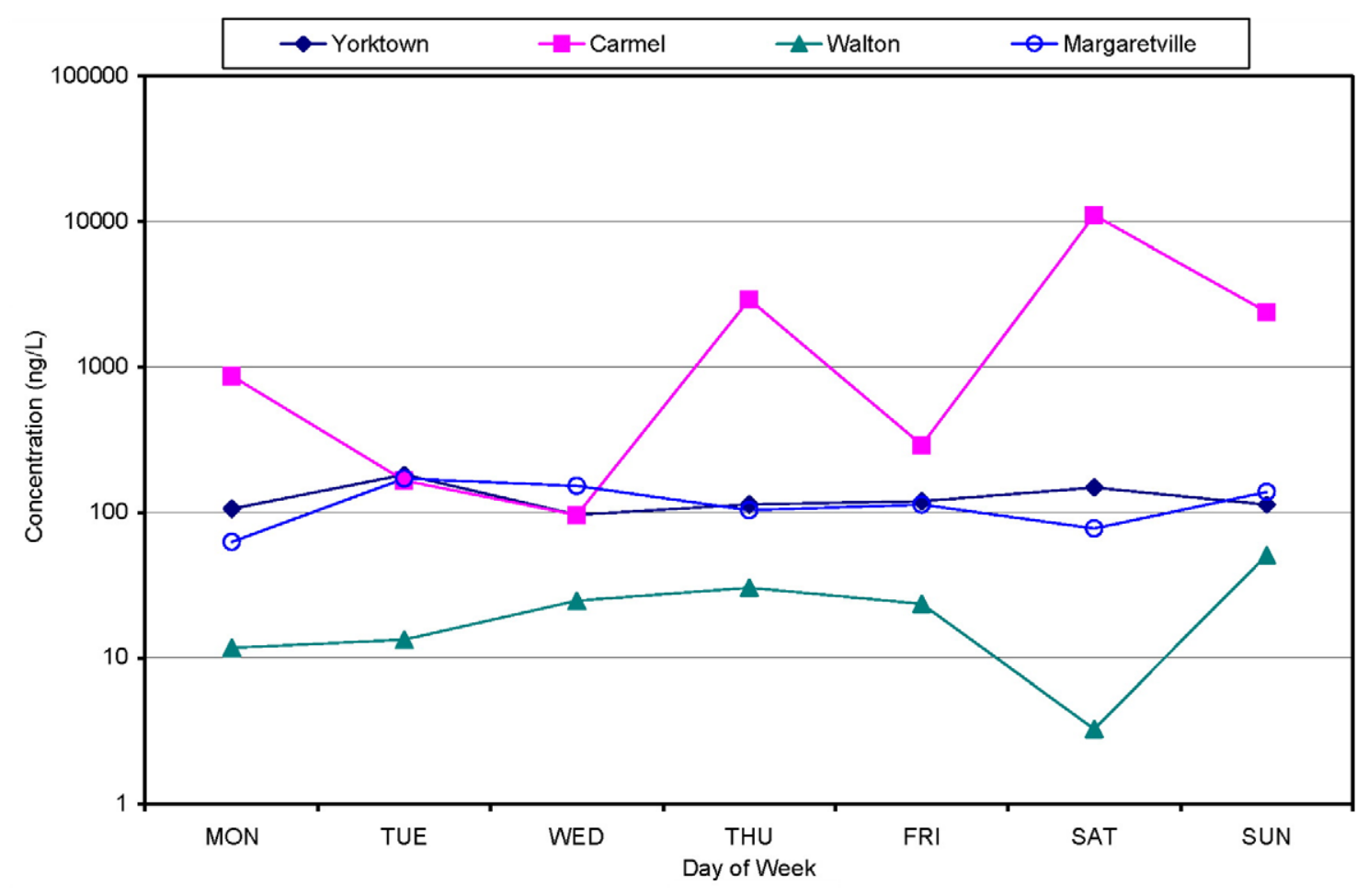

Fig. 3-Mean daily concentrations (ng/L) of trimethoprim in wastewater treatment plant effluents. Note: Detection limit for trimethoprim was $4 \mathrm{ng} / \mathrm{L}$. Each daily point represents the mean of 4-6 samples. 
a

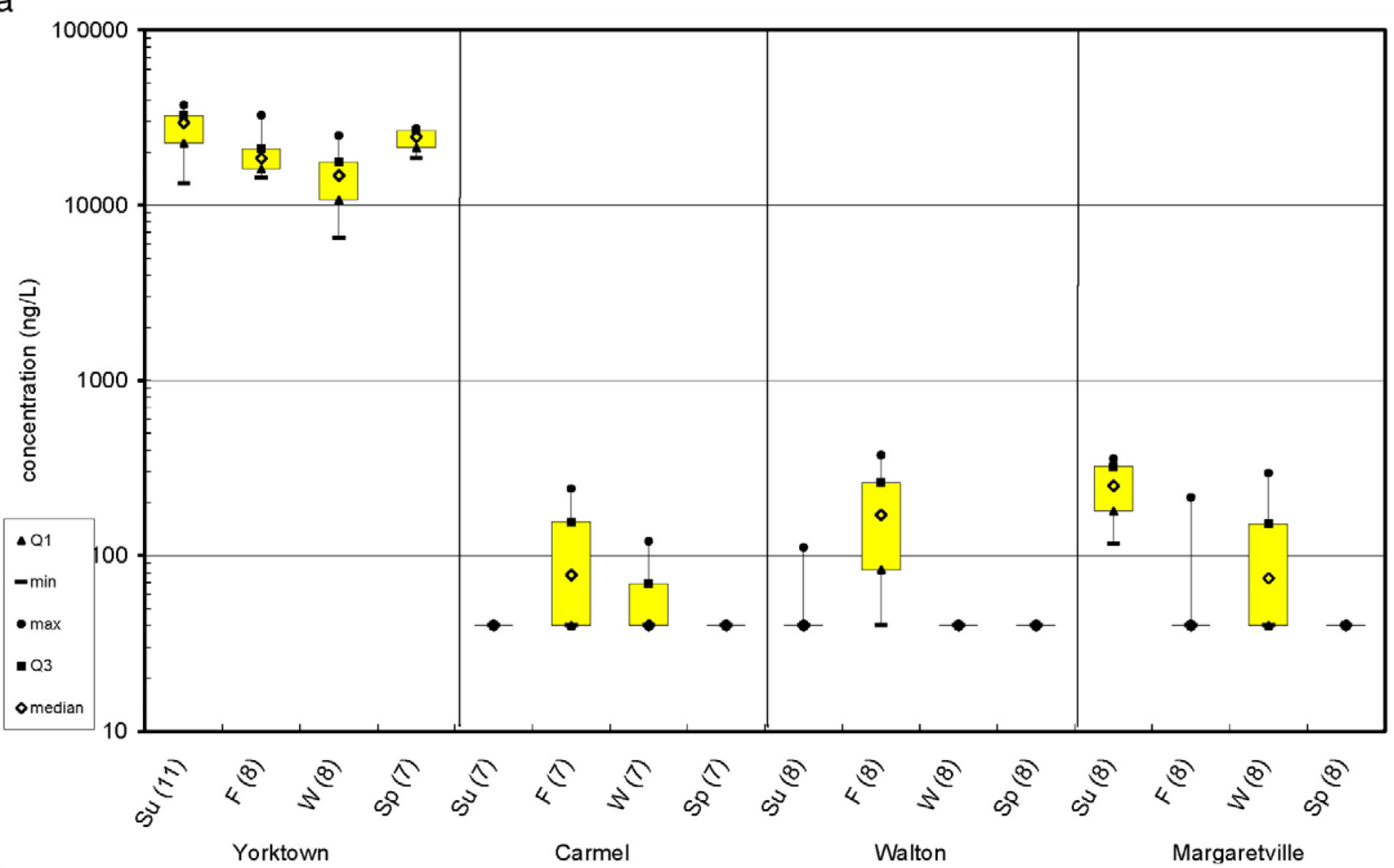

b

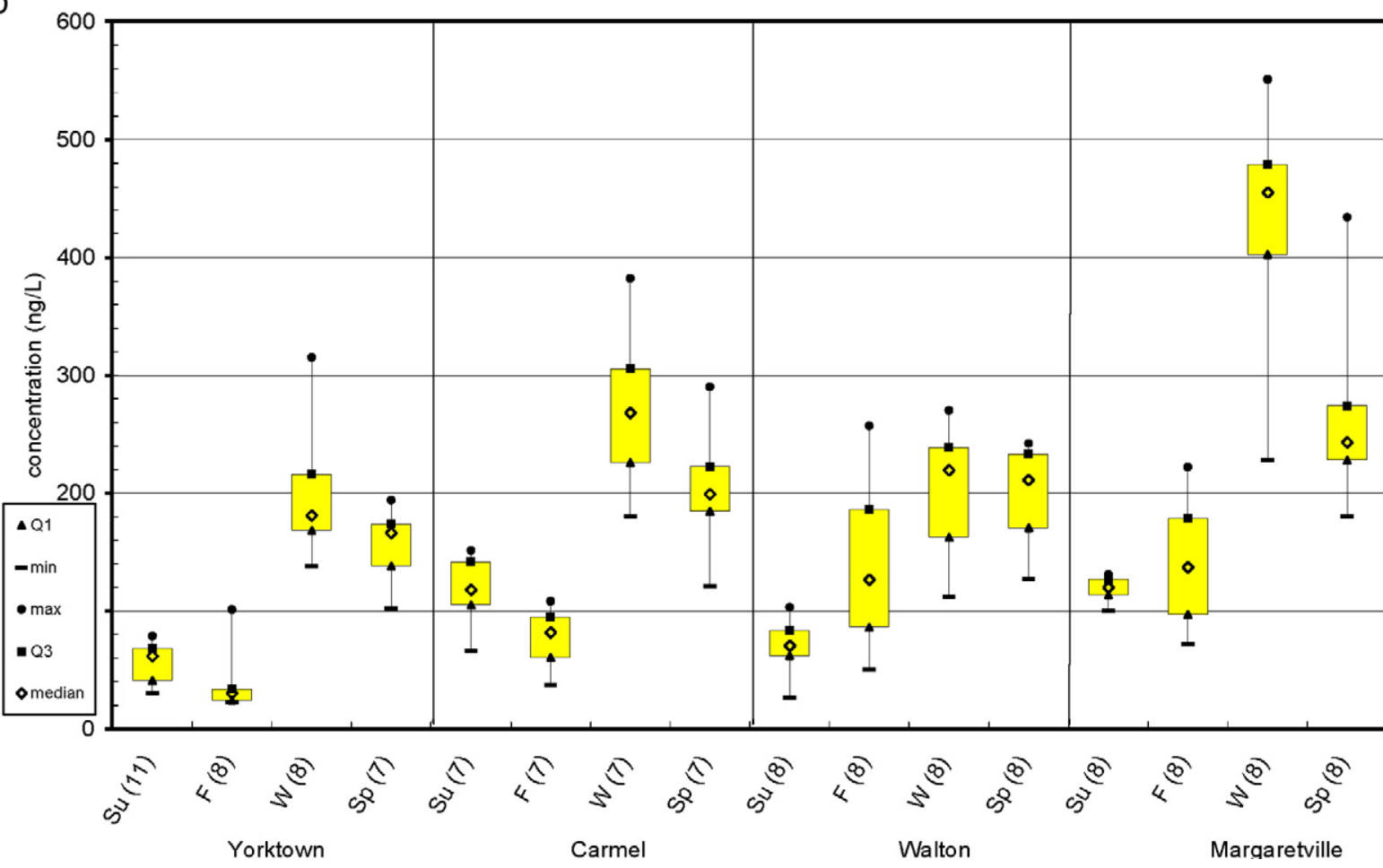

Fig. 4-a. Seasonal caffeine concentrations (ng/L) in wastewater treatment plant effluent. Detection limit for caffeine was $80 \mathrm{ng} /$ L. b. Seasonal carbamazepine concentrations (ng/L) in wastewater treatment plant effluent. Detection limit for carbamazepine was $20 \mathrm{ng} / \mathrm{L}$. Su: summer; F: fall; W: winter; Sp: spring. Sample numbers in parentheses. Q1: 1st quartile; min: minimum; max: maximum; Q3: 3rd quartile.

samples from Carmel had the highest median trimethoprim concentrations of any location $(6490 \mathrm{ng} / \mathrm{L}$ and $566 \mathrm{ng} / \mathrm{L}$, respectively), though it was not detected there in the fall.
This contrasts with Walton, which had its highest seasonal median in the fall (43 ng/L), but no detectable concentrations of trimethoprim in the winter samples. 


\subsection{Results from reservoir samples}

There were sporadic detections of two analytes in the reservoirs. Caffeine was detected in 7 of the 240 samples collected from the reservoirs, while ibuprofen was detected in 6 samples. Five of the caffeine detections (88-122 ng/L) and two of the ibuprofen detections (39 and $126 \mathrm{ng} / \mathrm{L}$ ) were from the CROGH location. CATALUM had the remaining two caffeine detections (177 ng/L and $103 \mathrm{ng} / \mathrm{L}$ ), which occurred in the summer and fall.

In addition, CATALUM and DEL18 each had two detections of ibuprofen. While CATALUM's detections were around the 20-ng/L detection limit (20 ng/L and $33 \mathrm{ng} / \mathrm{L}$ ), DEL18 had detections on consecutive days of $932 \mathrm{ng} / \mathrm{L}$ and $372 \mathrm{ng} / \mathrm{L}$. The former value is larger than that seen at three of the four WWTPs.

\section{Discussion}

In most studies where pharmaceuticals have been analyzed by LC/MS in either wastewater samples or river/lake water samples, the analyses were carried out in the MS/MS mode using triple quadrupole mass spectrometers (also referred to as tandem mass spectrometers) (Calamari et al., 2003; Castiglioni et al., 2006; Vanderford et al., 2003). In general, tandem MS/MS analysis of the daughter ions formed from fragmentation of molecular ions provides for both enhanced selectivity and an increased $\mathrm{S} / \mathrm{N}$ compared to analysis by selected ion monitoring (SIM) of molecular ions. However, with the ion trap MS used in our study, we found that MS/MS analysis was less sensitive than SIM analysis. Therefore, with the exception of amoxicillin and cephalexin, all the pharmaceuticals were analyzed by SIM. This could account for the high detection limits of some of the pharmaceuticals found in our study relative to detection limits found in studies where samples were analyzed by MS/MS using triple quadrupole mass spectrometers (e.g. Vanderford et al., 2003).

The absolute recovery values for the acid/neutral compounds were in the range of $4.5 \%$ to $34 \%$, which was considerably lower than the absolute recovery values obtained for the basic/ amphoteric compounds. The differences in recovery values between the two groups of compounds can be explained by differences in the complexity of the sample preparation procedures used for each group of compounds. The basic/ amphoteric compounds were extracted from water using a graphitized carbon cartridge and the concentrated extracts were then analyzed by LC/MS. The acid/neutral compounds were extracted with a disk containing styrene-divinyl benzene as an adsorbent, and the extracts were then solvent-exchanged for cleanup on a silica gel microcolumn prior to analysis by LC/MS. The cleanup step was required for the removal of background interference from WWTP effluent samples and from certain keypoint samples. However, the silica gel cleanup step resulted in reduced absolute recoveries. It should be understood that with the internal-standard-correction procedure we use to determine concentration levels, accurate results can be obtained when absolute recoveries are low.

While the recovery values for caffeine were very good, recoveries for atenolol, sulfamethoxazole, and trimethoprim were less accurate and precise. This can be explained by the structures of the internal standards. The caffeine internal standard was a ${ }^{13} \mathrm{C}$-labeled analog of caffeine and therefore this internal standard had the same chemical and physical properties as "native" caffeine prepared from the most abundant natural isotope of carbon, ${ }^{12} \mathrm{C}$. Since labeled analogs were not available for atenolol, sulfamethoxazole, and trimethoprim, we selected surrogates as internal standards for these compounds. While these surrogates had structures closely related to the structures of the three analytes, there could have been differences in recovery and/or response in the LC/MS instrument between an analyte and its surrogate.

The penicillins also proved to be difficult to extract from water samples. Since it is recognized that the $\beta$-lactam ring in penicillins is very unstable in the presence of certain solvents, such as methanol, these compounds are generally not included in monitoring surveys of pharmaceuticals in environmental waters. In the case of amoxicillin and cephalexin, sample matrix interfered with the protonated molecular ions, which required the use of MS/MS for the analysis of these compounds, resulting in very high MDL values.

For the estrogens, the combination of our high detection limits (30-40 ng/L), short half lives (2-3 h; Yu-Chen Lin and Reinhard, 2005), and predicted removal rates during wastewater treatment processes (74-84\%, Johnson et al., 2000), likely explains why we only detected E1 in one effluent sample, and E2 and EE2 not at all. Heberer (2002a) suggested WWTP effluent concentrations of EE2 should generally be less than $3 \mathrm{ng} / \mathrm{L}$, in which case we would not have detected them. Kolodziej et al. (2003) detected estrone at a maximum concentration of $12.3 \mathrm{ng} / \mathrm{L}$ in a study of eleven WWTPs with various treatment techniques and an engineered treatment wetland, while Joss et al. (2004) found a maximum E1, E2, and EE2 concentrations of 8.6, 0.5 , and $0.5 \mathrm{ng} / \mathrm{L}$ among three activated sludge WWTPs. The highest mean concentrations of E1, E2, and EE2 found by Cargouet et al. (2004) in the effluent of four French WWTPs were 7.2, 8.6, and $4.5 \mathrm{ng} / \mathrm{L}$, respectively. Such concentrations are well below those that could have been detected using our method.

\subsection{WWTP samples}

A study of European WWTPs showed poor removal (<10\%) of atenolol, carbamazepine, and trimethoprim using activated sludge (Paxéus, 2004). Italian WWTPs were not found to remove carbamazepine, while for atenolol, removal was higher in the summer than in the winter (55\% vs. 10\%) (Castiglioni et al., 2006). Another study found measurable concentrations (ranging from 3-241 ng/L) in two Italian rivers (Calamari et al., 2003). Other beta-blockers, like bisprolol, metoprolol, nadolol, and propanolol have been detected in effluents and surface waters (Ternes et al., 1998; Huggett et al., 2003; Fonon and Sedlak, 2005).

Carbamazepine was identified in every WWTP sample in our study. However, this compound was not detected in any reservoir sample, indicating that some dilution, degradation or removal process may be at work. It has been documented that carbamazepine is resistant to degradation in WWTPs. Miao et al. (2005) found a 29\% difference between influent and effluent concentrations, Heberer and Reddersen (2001) found 
only an 8\% difference, and others found no removal (Joss et al., 2005; Castiglioni et al., 2006). Clara et al. (2004) found no removal of carbamazepine using lab-scale experiments with varying solids retention times. Sampling at eleven full-scale WWTPs found only one with a removal rate over $20 \%$, and no difference was found in removal efficiency between activated sludge and trickling filter plants (Clara et al., 2004). Carballa et al. (2004) could not quantify carbamazepine in any 24-h composite sample (LOQ: $74 \mathrm{ng} / \mathrm{L}$ ) during their profile of an activated sludge WWTP in Spain.

At Yorktown, caffeine was detected in every sample. It is expected that most treatment facilities substantially reduce influent concentrations of caffeine (Heberer, 2002b; Miao et al., 2005). If our data represent only the small residual following caffeine's degradation, it may indicate very substantial input of caffeine to the plant, or perhaps more likely, that the plant's treatment operation degrades caffeine poorly. Lee and Rasmussen (2006) found a significant difference in caffeine concentrations between WWTPs using trickling filters and those using activated sludge, though only 6 and 8 samples (respectively) from those plants were analyzed. Although the caffeine concentrations found at Yorktown were very high compared to the other plants in our study as well as Lee and Rasmussen (2006), where the maximum reported concentration was $12,000 \mathrm{ng} / \mathrm{L}$, they are at the low end of the range found by Weigel et al. (2004). These authors detected caffeine in wastewater effluent in the range 20,000-293,000 ng/L, as well as concentrations of caffeine in sea water ranging from 7$87 \mathrm{ng} / \mathrm{L}$ in the Tromosø Sound on the Northern Coast of Norway.

The absence of biological nitrification processes at the WWTPs in our study (along with the low 4-ng/L detection limit) may help explain why $83 \%$ of the WWTP effluent samples had detectable trimethoprim concentrations. This process was shown in laboratory reactor experiments to significantly degrade trimethoprim during treatment, while other traditional processes, like activated sludge, were not effective (Perez et al., 2005; Paxéus, 2004). Of the seven WWTPs investigated by Gros et al. (2007), the six activated sludge plants were found inefficient at removing trimethoprim and carbamazepine.

The ibuprofen concentrations seen at Yorktown are higher than what was found recently in samples from Canadian WWTPs (<25 ng/L by Miao et al., 2002; and 100-300 ng/L by Stumpf et al., 1999) and some Norwegian WWTPs (20-680 ng/L; Weigel et al., 2004), but closer to those found in Swiss WWTPs (ND - 1300 ng/L; Tixier et al., 2003). WWTPs have been shown to remove ibuprofen efficiently, in some cases upwards of $90 \%$ removal (Joss et al., 2005), though this is considered dependent on the efficiency of the activated sludge process (Paxéus, 2004). Yorktown does not have activated sludge process, while Carmel (which had the fewest detections), does utilize this treatment technique.

\subsection{Reservoir samples}

In the reservoir samples, ibuprofen and caffeine were found above the detection limit in six $(2.5 \%)$ and seven $(2.9 \%)$ samples, respectively, of the 240 reservoir samples. However, it is unclear as to whether these compounds were present in the reservoir water or their detection was due to a sampling or sample analysis artifact. In one case, ibuprofen was detected in a DEL 18 sample at a concentration (932 ng/L) which was above those found in most WWTP effluent samples. Unfortunately, duplicate samples were not collected from these locations on the days when caffeine or ibuprofen were detected. It should be noted that we did not find similar contamination in samples from the West of Hudson locations, and that we did not detect caffeine and ibuprofen together in any reservoir sample. Therefore, the results may indicate that caffeine and ibuprofen are intermittently distributed in the reservoir samples, or that there was contamination during the sampling and/or analysis. Buerge et al. (2006) suggest that the presence of caffeine in receiving waters is indicative of an untreated wastewater discharge, as treatment efficiencies in most WWTPs are over 99\%. Although Yorktown does not have CSOs, there are other potential sources, such as septic systems or surface water runoff, which may have contributed to the caffeine detections in surface water.

\subsection{Daily and seasonal variation}

Few studies have evaluated a seasonality component for the pharmaceutical load in WWTP effluent. Hua et al. (2006) analyzed effluents from a Canadian activated sludge WWTP over three seasonal sampling periods, and found lower concentrations of trimethoprim in September than in the early spring and summer (means: 94, 313, and $344 \mathrm{ng} / \mathrm{L}$, respectively). Carbamazepine concentrations (means: 344, 219, and 304, respectively) were higher than the concentrations we found at Carmel, though the Canadian WWTP is a much larger plant. Another study of eight Canadian WWTPs found a median carbamazepine concentration of $43 \mathrm{ng} / \mathrm{L}$ in the spring, and a median of $110 \mathrm{ng} / \mathrm{L}$ in the summer (Brun et al., 2006). Carballa et al. (2004) analyzed various stages of treatment in an activated sludge WWTP in three seasons, and found winter ibuprofen concentrations in the influent and effluent about twice what was detected in the fall and spring for those compartments. Castiglioni et al. (2006) reported summer and winter removal rates (RR) for an Italian WWTP; among the compounds they identified, some had lower winter RR than summer RR, such as atenolol (10\% and 55\%) and ibuprofen (38\% and 93\%), while carbamazepine showed no removal in either season.

Daily variation in pharmaceutical concentration is even sparser than seasonal data, as many studies simply do not have the sample size to analyze this data. Clara et al. (2004) provide daily carbamazepine concentrations over four 7- to 10-day periods between October 2001 and December 2002, but these are for WWTP influent; the effluent data are not provided. Joss et al. (2005) looked at 24-h intra-day variation by collecting 8-h composite influent samples, which showed that carbamazepine loading primarily occurred between 0800 and $1600 \mathrm{~h}$

\section{Conclusions}

Five of the twelve analytes were consistently detected in the effluent of four wastewater treatment plants within the New 
York City Watershed. The type and concentration of analytes in the effluents differed between the plants and over the seasons. It is likely that the differences seen for some of the analytes (i.e. having a maximum and minimum during the same season at different plants) may be accounted for partially by the operational differences in the WWTPs, and/ or the differences in populations from which the plants receive waste. However, this does not explain the variation seen at individual plants. None of the analytes was detected in the surface waters of the West of Hudson reservoir samples, but caffeine and ibuprofen were detected infrequently in several East of Hudson reservoir samples. None of the other analytes was found in the surface water samples. The fate of the discharged pharmaceuticals in the watershed was not characterized and remains unknown. It is expected that investigation of other wastewater treatment plants in the NYC watershed would show that their effluents are also a potential source of pharmaceuticals to surface waters.

\section{Acknowledgements}

This work was funded by the USEPA under a NYC Watershed Protection Grant from the Safe Drinking Water Act. The grant was administered by the NYS Department of Environmental Conservation. We would like to thank the following people for their assistance in the design and implementation of this project: K. Markussen, NYSDEC; C. Cutietta-Olson, NYC Department of Environmental Protection; P. Phillips, USGS; and D. McChesney, USEPA. We would also like to thank K. Lewis and her staff at the NYCDEP Grahamsville Laboratory, as well as K. Mazor and other NYSDOH staff for their assistance during the sample collection phase.

\section{R E F E R E N C E S}

Buser H-R, Poiger T, Muller M. Occurrence and environmental behavior of the chiral pharmaceutical drug ibuprofen in surface waters and in wastewater. ES\&T 1999;33:2529-35.

Brun G, Bernier M, Losier R, Doe K, Jackman P, Lee H-B. Pharmaceutically active compounds in Atlantic Canadian sewage treatment plant effluents and receiving waters, and potential for environmental effects as measured by acute and chronic aquatic toxicity. Environ Toxicol Chem 2006;25(8): 2163-76.

Buerge I, Poiger T, Muller M, Buser H-R. Combined sewer overflows to surface waters detected by the anthropogenic marker caffeine. ES\&T 2006;40:4096-102.

Calamari D, Zuccato E, Castiglioni S, Bagnati R, Fanelli R. Strategic survey of therapeutic drugs in the Rivers Po and Lambro in Northern Italy. ES\&T 2003;37:1241-8.

Carballa M, Omil F, Lema J, Llompart M, Garcia-Jares C, Rodriguez I, Gomez M, Ternes T. Behavior of pharmaceuticals, cosmetics and hormones in a sewage treatment plant. Water Res 2004;38:2918-26.

Cargouet M, Perdiz D, Mouatassim-Souali A, Tamisier-Karolak S, Levi Y. Assessment of river contamination by estrogenic compounds in Paris area (France). Sci Total Environ 2004;342:55-66.

Castiglioni S, Bagnati R, Fanelli R, Pomati F, Calamari D, Zuccato E. Removal of pharmaceuticals in sewage treatment plants in Italy. ES\&T 2006;40:357-63.
Clara M, Strenn B, Kreuzinger N. Carbamazepine as a possible anthropogenic marker in the aquatic environment: investigations on the behaviour of Carbamazepine in wastewater treatment and during groundwater infiltration. Water Res 2004;38:947-54.

Fonon L, Sedlak D. Use of the chiral pharmaceutical propanolol to identify sewage discharges into surface waters. ES\&T 2005;39:9244-52.

Gros M, Petrovic M, Barcelo D. Wastewater treatment plants as a pathway for aquatic contamination by pharmaceuticals in the Ebro River Basin (Northeast Spain). Environ Toxicol Chem 2007;26(8):1553-62.

Halling-Sørenson B, Nors Nielsen S, Lanzky P, Ingerslev F, Holten Lützhøft H, Jergensen S. Occurrence fate and effects of pharmaceutical substances in the environment-a review. Chemosphere 1998;36(2):357-93.

Heberer T. Occurrence, fate, and removal of pharmaceutical residues in the aquatic environment: a review of recent research data. Toxicol Lett 2002a;131:5-17.

Heberer T. Tracking persistent pharmaceutical residues from municipal sewage to drinking water. J Hydrol 2002b;266: 175-89.

Heberer T, Reddersen K. Occurrence and fate of pharmaceutical residues in the aquatic system of Berlin as an example for urban ecosystems. Proceedings of the second international conference on pharmaceuticals and endocrine disrupting chemicals in water. October 9-11. Minneapolis, Minnesota: National Ground Water Association; 2001.

Heffler S, Smith S, Keehan S, Borger C, Clemens M, Truffer C. U.S health spending projections for 2004-2014. Health Affairs; 2005. p. W5-74-W5-85. Accessed May 10, 2005 at www.healthaffairs. org.

Hua W, Bennett E, Maio X-S, Metcalfe C, Letcher R. Seasonality effects on pharmaceuticals and s-triazine herbicides in wastewater effluent and surface water from the Canadian side of the Upper Detroit River. Environ Toxicol Chem 2006;25(9): 2356-65.

Huggett D, Khan I, Foran C, Schlenk D. Determination of beta-adrenergic receptor blocking pharmaceuticals in United States wastewater effluent. Environ Pollut 2003;121:199-205.

Johnson A, Belfroid A, Di Corcia A. Estimating steroid oestrogen inputs into activated sludge treatment works and observations on their removal from the effluent. Sci Total Environ 2000;256:163-73.

Joss A, Andersen H, Ternes T, Richle P, Siegrist H. Removal of estrogens in municipal wastewater treatment under aerobic and anaerobic conditions: consequences for plant optimization. ES\&T 2004;38:3047-55.

Joss A, Keller E, Alder A, Gobel A, McArdell C, Ternes T, Siegrist H. Removal of pharmaceuticals and fragrances in biological wastewater treatment. Water Res 2005;39:3139-52.

Kolodziej E, Gray J, Sedlak D. Quantification of steroid hormones with pheromonal properties in municipal wastewater effluent. Environ Toxicol Chem 2003;22(11):2622-9.

Kolpin D, Furlong E, Meyer M, Thurman E, Zaugg S, Barber L, Buxton H. Pharmaceuticals, hormones, and other wastewater contaminants in U.S. streams, 1999-2000 - a national reconnaissance. ES\&T 2002;36:1202-11.

Lee C, Rasmussen T. Occurrence of organic wastewater compounds in effluent-dominated streams in Northeastern Kansas. Sci Total Environ 2006;371:258-69.

McArdell C, Molnar E, Suter M, Giger W. Occurrence and fate of macrolide antibiotics in wastewater treatment plants and in the Glatt Valley Watershed, Switzerland. ES\&T 2003;37:5479-86.

Miao X-S, Koenig B, Metcalfe C. Analysis of acidic drugs in the effluents of sewage treatment plants using liquid chromatography-electrospray ionization tandem mass spectrometry. J. Chromatogr., A 2002;952:139-47. 
Miao X-S, Yang J-J, Metcalfe C. Carbamazepine and its metabolites in wastewater and in biosolids in a municipal wastewater treatment plant. ES\&T 2005;39:7469-75.

National Association of Chain Drug Stores. Table no. 122. Retail prescription drug sales: 1995 to 2003. Statistical abstract of the United States. Washington, D.C.: U.S. Census Bureau; 2004-2005. p. 96. Available at: http://www.census.gov/prod/ www/statistical-abstract-04.html.

NDCHealth Corporation. 2004 Top 10 products by total prescription count. Accessed May 9, 2005, at: http://www. ndchealth.com/press_center/uspharmaindustrydata/ 2004top10productsbytotalprescription.htm.

New York City Department of Environmental Protection. New York City 2005 drinking water supply \& quality report. Flushing, New York: NYCDEP; 2006.

New York State Department of Environmental Conservation. Descriptive data of municipal wastewater treatment plants in New York State. Albany, New York: NYSDEC; 2004.

Paxéus N. Removal of selected non-steroidal anti-inflammatory drugs (NSAIDs), gemfibrozil, carbamazepine, $\beta$-blockers, trimethoprim, and triclosan in conventional wastewater treatment plants in five EU countries and their discharge to the aquatic environment. Water Sci Technol 2004;50(5):253-60.

Perez S, Eichhorn P, Aga D. Evaluating the biodegradability of sulfamethazine, sulfamethoxazole, sulfathiazole, and trimethoprim at different stages of sewage treatment. Environ Toxicol Chem 2005;24:1361-7.

Seiler R, Zaugg S, Thomas J, Howcroft D. Caffeine and pharmaceuticals as indicators of waste water contamination in wells. Ground Water 1999;37:405-10.

Stackelberg P, Furlong E, Meyer M, Zaugg S, Henderson A, Reissman D. Persistence of pharmaceutical compounds and other organic wastewater contaminants in a conventional drinking-water treatment plant. Sci Total Environ 2004;329:99-113.

Stumpf M, Ternes T, Wilken R, Rodrigues S, Baumann W. Polar drug residues in sewage and natural waters in the state of Rio de Janeiro, Brazil. Sci Total Environ 1999;225:135-41.

Ternes T. Occurrence of drugs in German sewage treatment plants and rivers. Water Res 1998;32:3245-60.

Ternes T, Hirsch R, Mueller J, Haberer K. Methods for the determination of neutral drugs as well as betablockers and beta(2)-sympathomimetics in aqueous matrices using GC/MS and LC/MS/MS. Fresenius J Anal Chem 1998;362(2):329-40.

Tixier C, Singer H, Oellers S, Muller S. Occurrence and fate of carbamazepine, clofibric acid, diclofenac, ibuprofen, ketoprofen, and naproxen in surface waters. ES\&T 2003;37:1061-8.

United States Code of Federal Regulations. Appendix B to part 136 - definition and procedure for the determination of the method detection limit-revision 1.11. 40 CFR 136.6; Revised July 1, 2007. Available at: http://www.access.gpo.gov/ nara/cfr/waisidx_07/40cfr136_07.html.

Vanderford B, Pearson R, Rexing D, Snyder S. Analysis of endocrine disruptors, pharmaceuticals and personal care products in water using liquid chromatography/tandem mass spectrometry. Anal Chem 2003;75:6265-74.

Weigel S, Berger U, Jensen E, Kallenborn R, Thoresen H, Hühnerfuss $\mathrm{H}$. Determination of selected pharmaceuticals and caffeine in sewage and seawater from Troms $\varnothing /$ Norway with emphasis on ibuprofen and its metabolites. Chemosphere 2004;56:583-92.

Yu-Chen Lin A, Reinhard M. Photodegradation of common environmental pharmaceuticals and estrogens in river water. Environ Toxicol Chem 2005;24:1303-9. 